\title{
Managing In-Library Use Data: Putting a Web Geographic Information Systems Platform through Its Paces
}

\begin{abstract}
Web Geographic Information System (GIS) platforms have matured to a point where they offer attractive capabilities for collecting, analyzing, sharing, and visualizing in-library use data for space-assessment initiatives. As these platforms continue to evolve, it is reasonable to conclude that enhancements to these platforms will not only offer librarians more opportunities to collect in-library use data to inform the use of physical space in their buildings, but also that they will potentially provide opportunities to more easily share database schemas for defining learning spaces and observations associated with those spaces. This article proposes using web GIS, as opposed to traditional desktop GIS, as an approach for collecting, managing, documenting, analyzing, visualizing, and sharing in-library use data and goes on to highlight the process for utilizing the Esri ArcGIS Online platform for a pilot project by an academic library for this purpose.
\end{abstract}

\section{INTRODUCTION}

A geographic information system (GIS) is a computer program for working with geographic data. A GIS is an ideal tool for capturing data about library learning spaces because they can be described by a geographic area. The learning spaces might be small or large, irregularly shaped or symmetrical-either way, the shape can be described by a set of geographic coordinates. Tools for storing, managing, documenting, analyzing, and visualizing geographic data can all be found in a GIS. The locations and shapes of geographic features (such as library learning spaces) as well as attributes of those features (such as the type of learning space) can be captured in a GIS.

The roots of GISs stretch back to the 1960s. Goodchild characterizes GISs' advances in spatial analysis during the 1970s and the growth of GIS in the 1980s, coinciding with the proliferation and affordability of desktop computers. ${ }^{1}$

The enhancement of GIS software from desktop computer applications to online platforms has been underway for some time. The origins of web GIS can be traced back to 1990s, but it is only since the mid2000 s that products have really matured to a point where they can be viable alternatives to their desktop counterparts. Web GIS first appears in 1993 when Xerox Corporation's Palo Alto Research Center created an online map viewer. ${ }^{2}$ Their map viewer, running in a web browser, was the first demonstration of performing GIS tasks without GIS software installed on a local computer. Even though this early web-based GIS application had limited capabilities, the potential of performing GIS operations from computers anywhere and anytime was recognized. The possible capabilities of web GIS began to be more fully discussed in the mid-1990s. ${ }^{3}$ Web GIS software became available in earnest in 1996 as GIS companies began releasing commercial offerings. ${ }^{4}$ The first two decades of this century have seen web GIS explode in functionality and scope to become an integral part of most GISs.

Bruce Godfrey (bgodfrey@uidaho.edu) is GIS Librarian and Rick Stoddart (rstoddart@uidaho.edu) is Education Librarian at the University of Idaho Library. 
In late 2012, a collaborative mapping platform hosted by Esri (Environmental Systems Research Institute) named ArcGIS Online (https://www.arcgis.com/) was released. Esri is a GIS software company that was founded in 1969, and its products are used by more than 7,000 colleges and universities across the globe. ${ }^{5}$ The collaborative platform enables users to create, manage, analyze, store, and share maps, applications, and data on the internet. GIS software continues to evolve from desktop computer programs to specialized software applications (i.e., apps) that are part of a web-focused platform. This transformation is profoundly growing the accessibility of the technology to a broader array of users. What was once a technology reserved for geographic information professionals because of its complexity and cost has now been streamlined and put in the hands of nonprofessionals who want to take advantage of its many possibilities. It is no longer reserved for academic disciplines such as geographic information science and remote sensing science; instead, GIS has seen its use grow in humanities and social science to the point where libraries are developing targeted services for these disciplines. ${ }^{6}$ Professionals are afforded the ability to share their data more easily, and nonprofessionals are able to utilize those data to create information and knowledge more easily.

This transformation bodes well for libraries because it lowers technological hurdles that might have precluded the technology's use for space-assessment and other place-based initiatives in the past. Now that software-as-a-service (SaaS) mapping platforms such as Mango, GIS Cloud, and ArcGIS Online enable users to access capabilities over the internet, there is no server software for users to install or licensing to configure. Additionally, the training required by personnel to gather, utilize, and manage data has been greatly reduced compared to its desktop predecessor. Academic libraries, and libraries in general, stand to gain from the evolution.

\section{THE USE OF DESKTOP GIS FOR SPACE ASSESSMENT}

The value of space planning efforts in libraries and the observational methods employed to conduct such activities have been well articulated in library research. The use of desktop GIS as a tool for collecting inlibrary use data in academic libraries has been present for more than a decade. Bishop and Mandel show that libraries' use of GIS falls into two broad categories, analyzing service area populations and facilities management, the latter of which encompasses "in-library use and occupancy of library study space." ${ }^{7}$ Work related to the use of GIS to study library-patron spaces is discussed below.

In the past twenty years, academic libraries have seen many transformations in their roles on college and university campuses. GIS technologies have helped document and respond to those transformations. Xia outlined the value of using GIS as a tool for space management in academic libraries more than a decade ago because of its "capacity for analyzing spatial data and interactive information." 8 In one study, Xia describes using Esri ArcView 3.x desktop software for library space management. ArcView was Esri's first GIS software to have a graphical user interface; predecessors had command-line interfaces. Xia mentions the use of, at that time, the emerging ArcGIS product, which went on to replace ArcView 3.x. GIS proved to be a valuable tool for Xia to track the spatial distribution of books in the library environment. ${ }^{9}$ Xia went on to measure and visualize the occupancy of study space using ArcView. ${ }^{10}$ Lastly, Xia used ArcView as an item-locating system within the physical space of the library. ${ }^{11}$

More recently, Mandel utilized MapWindow, an open-source desktop GIS originally developed at Idaho State University, for creating maps of fictional in-library use data. ${ }^{12}$ Mandel's process demonstrated how a GIS could be utilized to visualize the use of library spaces for marketing materials and services as well as graphically depicting a library's value. Coyle argued for the use of GIS as a tool to analyze the interior space of the library, and specifically the library collection itself, while not implementing a system with any 
specific GIS package. ${ }^{13}$ Given and Archibald detailed their use of visual traffic sweeps as an approach to collect and visualize in-library use data. ${ }^{14}$ Their workflow involved utilizing a Microsoft Excel spreadsheet to capture data and then importing the data into ArcGIS to query and visualize the data. Therefore, GIS wasn't used for data capture; it was used toward the end of the process to visualize these data.

While the body of work details the use of desktop GIS for working with in-library use data, collaborative web GIS platforms now offer opportunities to advance existing research in this arena by streamlining datacollection workflows, sharing database schemas, and enabling broader collaboration with peers, thereby potentially creating opportunities for new research. Fusing the capabilities of these new platforms with traditional observational methods of gathering data on how people are using library spaces extends the body of knowledge and offers interesting new opportunities for research such as cross-institutional comparisons. It is critical for twenty-first-century academic libraries to collect such data to continue to evolve with the changing needs of digital-age campus research and culture.

\section{UTILIZING A CLOUD-BASED PLATFORM FOR LEARNING SPACE ASSESSMENT}

Discussed below is the approach employed for this pilot project to use web GIS to collect, manage, share, and visualize information about library learning spaces. This pilot project utilized the Esri ArcGIS Online platform and client applications accessing that platform (see figure 1). Collector for ArcGIS (http://doc.arcgis.com/en/collector), a ready-made app, was used for data collection. ArcGIS Desktop (http://desktop.arcgis.com) was used at the outset to create the initial database schema. A custom HTML/JavaScript web application was developed to better enable library administrators to visualize the data as a map, table, or chart. Prior to the implementation of this pilot project, the Circulation Department conducted floor sweeps for safety purposes (e.g., making sure certain doors were locked), but space assessment data had never been gathered for the library.

\section{Research Study Location}

All observations were taken during fall 2016 and spring 2017 at the University of Idaho Library and the Gary Strong Curriculum Center. This article focuses on the implementation of the platform for use at the Library.

The first floor of the University of Idaho Library underwent a remodel during winter 2016. The remodel included new furniture and different configurations of areas better customized for learning and studying. Spaces such as group study, booths, and brainstorming spaces figured prominently in the remodel.

Additionally, expanded food and beverage options and having proximity to open seating areas located near natural light provide a welcoming environment. Library hours were also expanded to 24 hours per day, 5 days a week. With these changes arose the desire to digitally collect data to learn about the use of these new locations by patrons. Utilizing these data to inform decision-making about future changes to the physical spaces in the library, as well as connecting library learning spaces to campus learning outcomes, were goals of this research. 


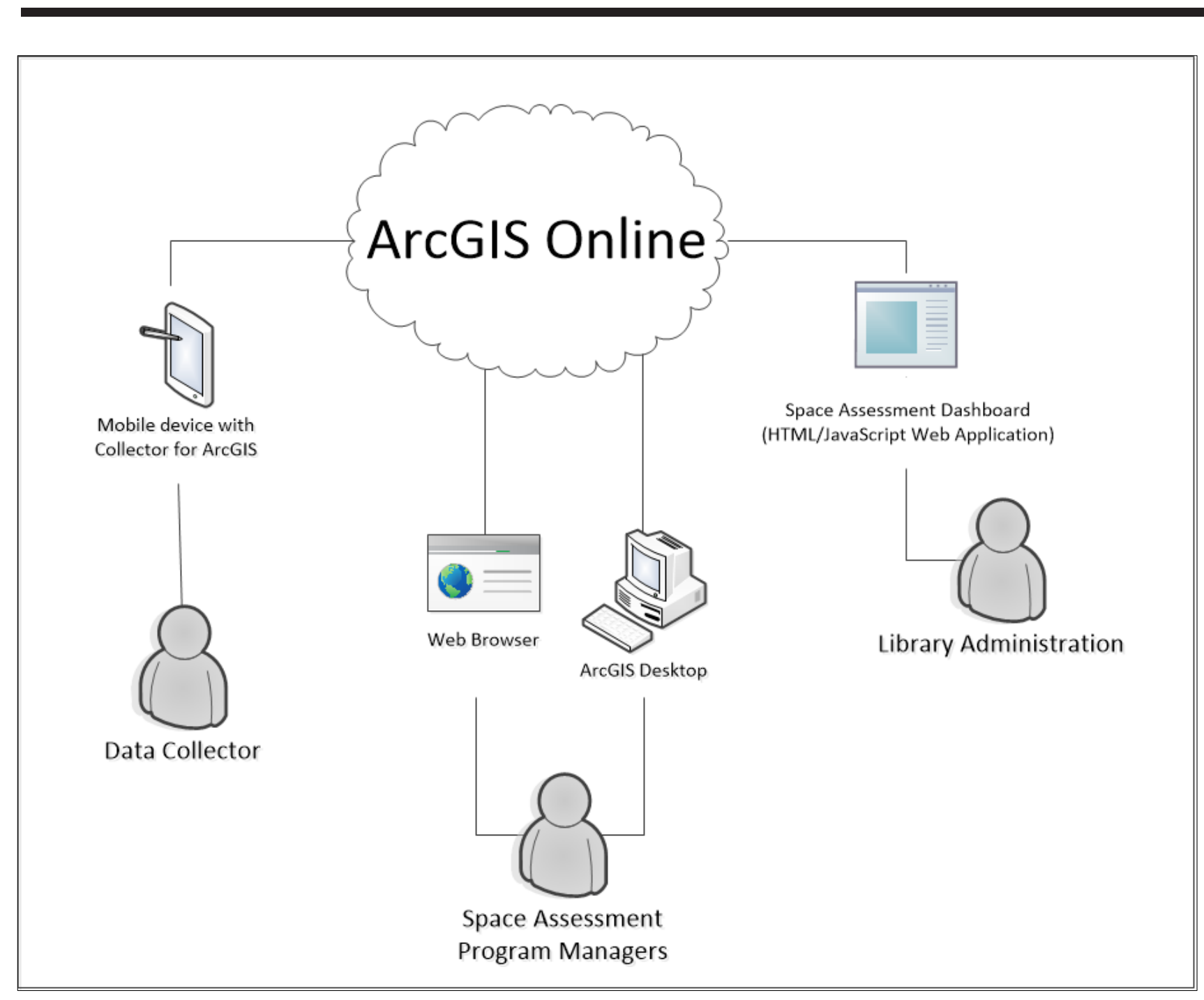

Figure 1. Infrastructure for the pilot project.

\section{Selecting the ArcGIS Online Platform}

Using locally existing resources to implement this pilot project was a requirement. Funding was not available to purchase server software or hardware. Personnel time could be carved out of existing positions for this effort, but money was not available to hire additional personnel. The University of Idaho Library does not have a dedicated IT unit, so choices were limited. Purchasing business-intelligence software such as Tableau was cost prohibitive. An open-source tool such as Suma, developed by North Carolina State University Libraries, was not a practical option in this case because the system requirements did not align with the expertise of existing personnel. ${ }^{15}$

Fortunately, the ArcGIS Online platform was available for this research at no cost to the library, and existing personnel had experience using the platform. The University of Idaho participates in, and contributes financially to, a State of Idaho higher education site license for Esri software. The software is then available to personnel across the institution for research, teaching, and, to a lesser extent at this time, administrative purposes. Since ArcGIS Online is a cloud platform, there is no server software to install and update and no server hardware to configure. Additionally, the University of Idaho GIS librarian was familiar with the capabilities of the platform and available to actively participate in this research. 
In short, researchers' access to and existing expertise with the ArcGIS Online platform, coupled with the extensive capabilities of the platform itself, made it the best choice for this research.

\section{Pilot Project Design}

A public services librarian and the GIS librarian assumed leadership roles for the pilot project. The public services librarian led tasks associated with defining the learning (i.e., the data-collection) spaces, defining the data fields and domains for those spaces, and overseeing personnel responsible for collecting these data. The GIS librarian led tasks associated with creating the database schema, creating the geographic features representing the learning spaces, creating a web application to visualize the data, and managing content on the ArcGIS Online platform. Library personnel were responsible for collecting the data.

\section{Gathering ancillary data}

Having building floor plans in a digital format was helpful for data collectors to orient themselves in the space when looking at a map on a mobile device. Our research team was able to acquire georeferenced building floor plans for our institution from the Information Technology Services unit on campus. Each of the four floors of the library were published to ArcGIS Online as Hosted Tile Layers to serve as a frame of reference for data collectors.

\section{Managing content and users}

ArcGIS Online provides the ability to create and define groups. Groups are collections of items that can be shared among named users. Individual user accounts for each project participant were created, and a group containing items for this pilot project to be shared among those users was created. This approach allowed all data associated with the project to be private and only shared among personnel participating in the project.

\section{Database design}

The primary knowledge product resulting from this research was a web application containing a twodimensional map, tables, and charts. A geodatabase, which is an assemblage of geographic datasets, needed to be designed and created to provide data to the web application. ${ }^{16}$

Designing a geodatabase begins with defining the operational layers required to gather information. ${ }^{17}$ For this pilot project, one operational layer depicting individual learning spaces was required (see table 1).

Table 1. Description of the learning spaces layer

\begin{tabular}{|l|l|}
\hline Layer & Learning spaces \\
\hline Map use & Learning spaces define areas intended for a specific type of learning \\
\hline Data source & Digitized using building floor plans as a frame of reference \\
\hline Representation & Polygons \\
\hline
\end{tabular}

The learning spaces layer was used to store the geometry of the individual learning spaces. A table to store observations for each learning space was needed, and a relationship between each individual space and the observations for each space was required (see figure 2). The relationship binds observations to their appropriate learning spaces. The relationship was defined to allow one learning space to relate to many observations for that space. 


\section{Geodatabase}

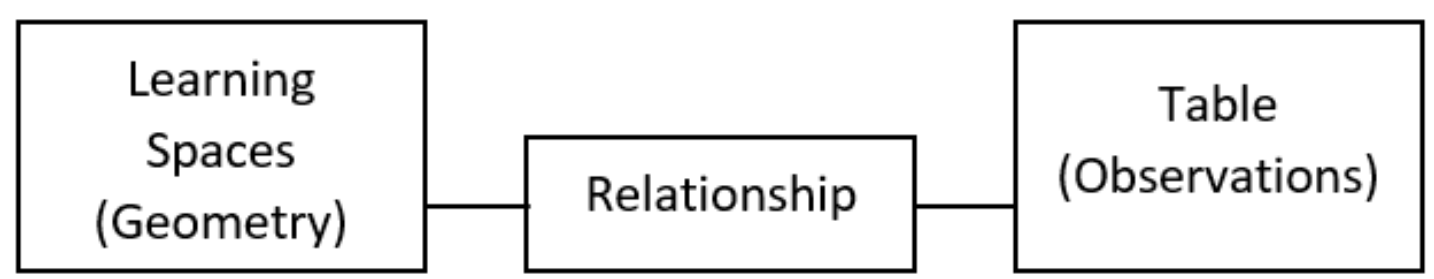

Figure 2. Data elements of the geodatabase.

Fields, analogous to columns in a spreadsheet, were defined for the learning spaces and observations table to store descriptive information. For example, a friendly name was assigned to each learning space.

Additionally, domains were defined to manage valid values for specific fields. Domains were necessary for quality control and quality assurance to enforce data integrity, enabling data collectors to pick items from lists rather than having to type the item names. This feature eliminates potential data-collection errors. Field names, data types, field descriptions, and domains for this pilot project can be found in the appendix.

\section{Defining data-collection spaces}

A template was created to define the information required to create each learning space feature. These features were created by digitizing them on a computer screen for each of the four floors of the library using the building floor plans as a frame of reference. Ten learning spaces were defined for the first floor of the library and one each for floors 2, 3, and 4. A map for each floor was created and published to ArcGIS Online as a Hosted Feature Layer. ${ }^{18}$ Each map contained two layers: one for the floor plan and one for the learning spaces (figure 3). Library personnel used these maps to collect data.

\section{Data collection}

Data collection was accomplished using Collector for ArcGIS installed on mobile devices. This eliminated the need for any software-development costs for data collection. Collector for ArcGIS is a ready-made ArcGIS Online application that is designed to provide an easy-to-use interface for collecting location-based data. The software was installed on a variety of devices, including a Samsung Galaxy tablet, a Surface tablet, and an Apple iPad. The online collection mode was enabled during collection, resulting in data being transferred real-time to ArcGIS Online. The software can collect data in an offline mode, but, because strong internet connections were available in both campus buildings, the online mode was utilized.

The collection workflow consisted of library personnel traversing the floors of the library and recording data about the number of users in each space, what the users were doing in the space, and entering additional context comments if necessary. Library staff were encouraged to use their own expertise and observational cues (e.g., textbooks present) when recording data associated with patron activities in library spaces. The date, time, and name of the data collector was recorded automatically, an option available through the ArcGIS Online platform. The user interface for the software was friendly and intuitive and required minimal training (figure 4). A list was provided to select the type of use for the selected space. Data were accessible via ArcGIS Online immediately following collection. 


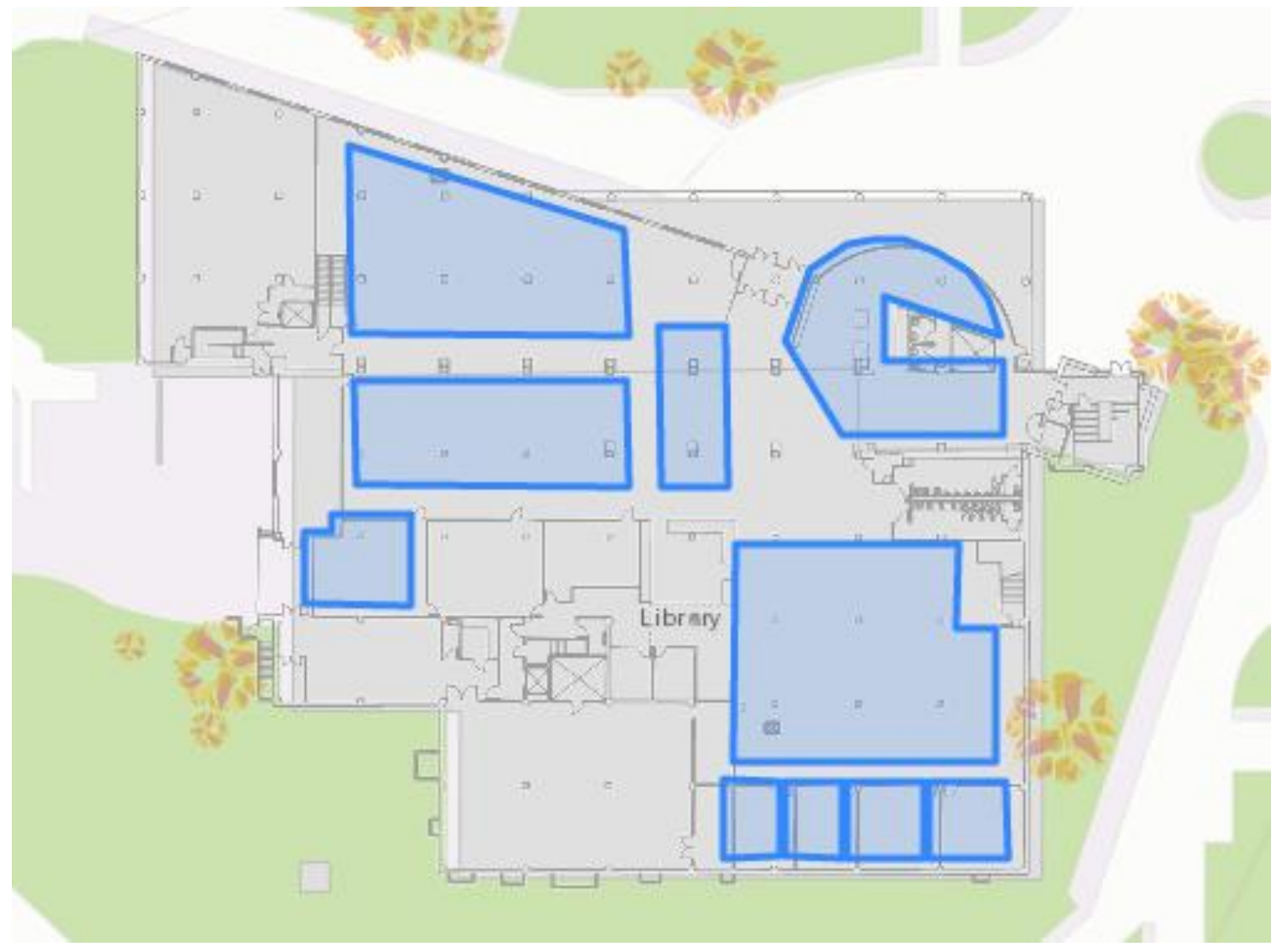

Figure 3. First floor learning spaces of the University of Idaho library overlaid on the building floor plan.

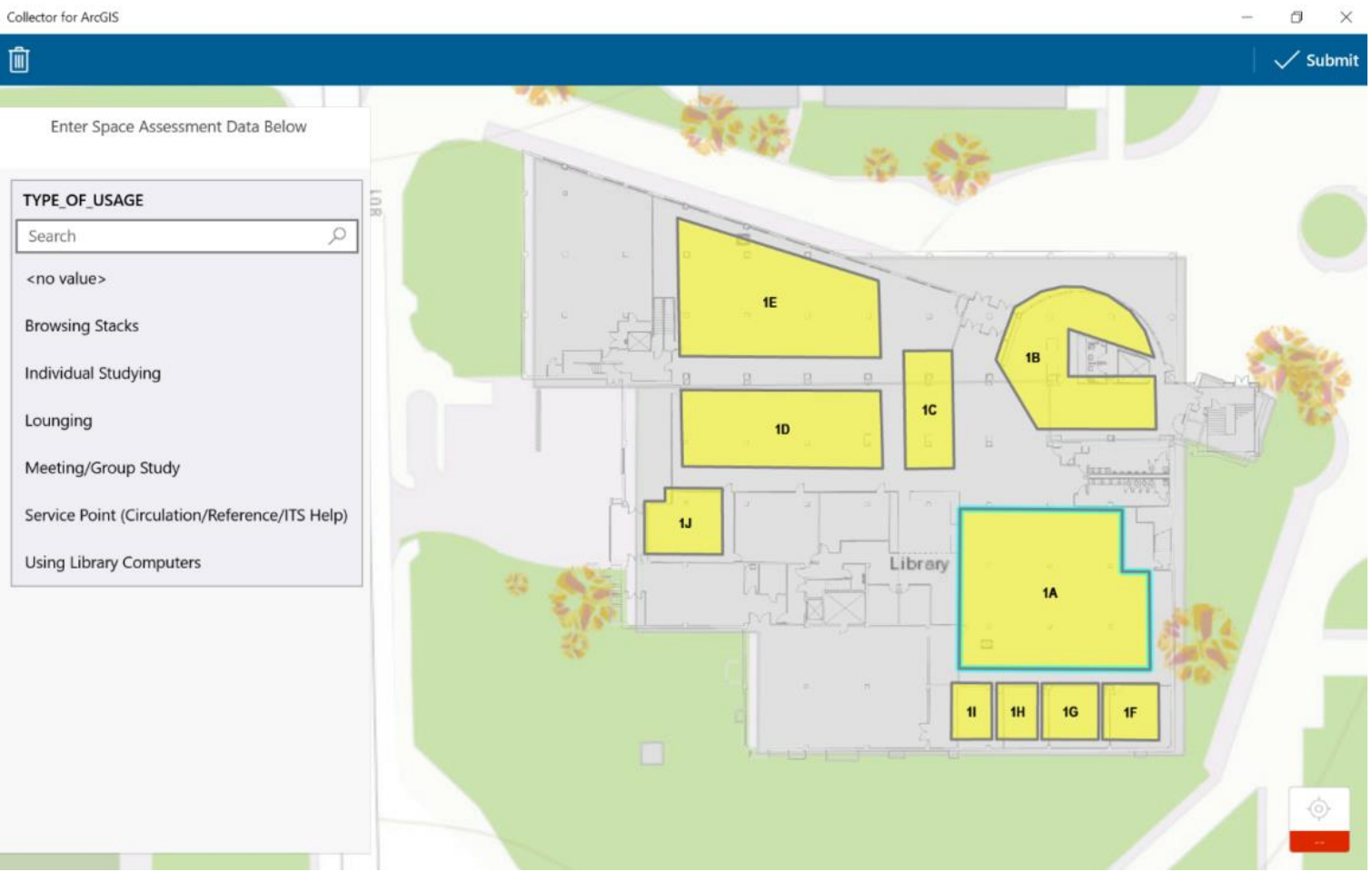

Figure 4. The Collector for ArcGIS user interface utilized for data collection. 


\section{RESULTS OF USING WEB GIS}

Web GIS, specifically ArcGIS Online, offered the functionality required for collecting and managing in library use data. Additionally, the platform offers librarians supplementary opportunities for collaborative space-assessment projects. While the ArcGIS Online platform proved to be useful for this pilot project, some of the advantages and limitations encountered are discussed below.

\section{Advantage: Ease of Use Through Targeted Applications}

Esri software has been used in academia for decades. While the early command-line versions and later desktop versions were the playground of those with GIS training, web GIS applications have a decidedly friendlier interface because of the ability to customize applications on the platform for specific purposes. For example, applications with management functionality can be separated from applications intended for data gathering. The need for excessive functionally to be included in one interface is replaced with a more modular framework, resulting in less complex user interfaces as seen in many desktop GIS programs. While some personnel involved with this project had used Esri software for many years and were familiar with the capabilities of the ArcGIS Online, they had not used the platform for data collection prior to this project. Managing users and content for the project proved to be straightforward. It was made even easier when enterprise logins were configured, which allowed personnel to sign in using their institutional user name and password. Authoring the database schema, creating the necessary maps, and publishing those maps as hosted services was not complicated for those with basic desktop and web GIS knowledge. Those responsible for collecting data needed little training using Collector for ArcGIS to begin data collection. Finally, librarians with no GIS background were able to export the data to a familiar format (commaseparated values) to begin analysis using software such as Excel. In short, authoring the database and map services remains best handled by those with GIS experience. However, targeted application interfaces enable user without GIS experience to collect and work with data.

\section{Advantage: Participation in Enterprise Architecture}

Conducting library research on a platform many faculty, students, and staff are beginning to use for research, learning, and administration places librarians within the same collaborative space as the communities they are serving. In the case of this research, our need for building floor plans presented opportunities to more broadly discuss enterprise GIS at our institution by sharing this information. Interaction took place between the Library, Facilities Services, and Information Technology Services, resulting in a cultivation of relationships around data sharing. Furthermore, integration of our enterprise security with the ArcGIS Online platform adds a level of legitimacy to geospatial data management efforts.

\section{Advantage: Potential for Cross-Institutional Collaborative Projects}

The potential for cross-institutional collaboration on library-space assessment and other projects should not be overlooked when using the ArcGIS Online platform. Such collaborations are even more manageable because Esri software is being used by more than 7,000 colleges and universities across the globe. Even though cross-institutional collaboration was not a goal of this research, the opportunities for projects or programs of this nature became abundantly clear. Items created in ArcGIS Online can be shared between organizations. Simply sharing a library-space-assessment database schema with librarians at other institutions would allow them to quickly implement a similar project on the ArcGIS Online platform. This opens the door to new research opportunities. The functionality exists for one institution to host a database that personnel from multiple institutions could populate. A single dataset containing learning spaces of multiple institutions with multiple contributors could be created, managed, and analyzed collaboratively. This could enable lower-resource libraries to participate in projects with larger institutions as economies 
of scale are realized. And it offers the ability to undertake projects across multiple institutions to explore broader space assessment or other research questions.

\section{Limitation: Updating Hosted Feature Service Schemas}

The ability to author and edit schemas entirely in ArcGIS Online has not yet matured to a point where it matches the abilities of its desktop counterpart. Specifically, updating a published schema is currently difficult to accomplish in ArcGIS Online because a user-friendly interface does not exist. However, the task can be accomplished by editing the JavaScript Object Notation (JSON) of the hosted feature service. While this is a current limitation for managers of the hosted feature service and not data collectors, it is anticipated that this will be addressed in future updates.

\section{Limitation: User Interface for Standards-Based Metadata}

Items created as part of the pilot project were documented using the metadata editor provided in ArcGIS Online. ArcGIS Online's users can create and maintain geospatial standards-based metadata for content. However, the user interface for creating metadata based on either the ISO 19115-series or Federal Geographic Data Committee (FGDC) Content Standard for Digital Geospatial Metadata (CSDGM) could be improved by simplifying its complexity and allowing for batch updating specific elements. Item documentation for the platform focuses on creating and editing elements of ArcGIS-format metadata. It should be noted, and potentially added as a point of concern for librarians, that the ability to author and edit metadata based on the ISO and CSDGM standards was introduced three years after the initial release of ArcGIS Online.

\section{Limitation: Visualizing Data in Related Tables}

The ability to visualize data collected as part of this project using ready-made applications in ArcGIS Online yielded unsatisfactory results. The primary limitation was related to working with repeated measurements for the learning spaces. Ready-made applications like Web AppBuilder and Operations Dashboard have limited support for a user-friendly presentation of repeated learning-space observation. Therefore, a custom web application was developed by a University of Idaho student using the Esri JavaScript application programming interface (API). The application provides the ability to select a date range, a time scope (e.g., daytime, nighttime, all hours), a building, and a floor to visualize the data. The learning spaces are colored by the total number of users in a space on the basis of the parameters selected (see figure 5).

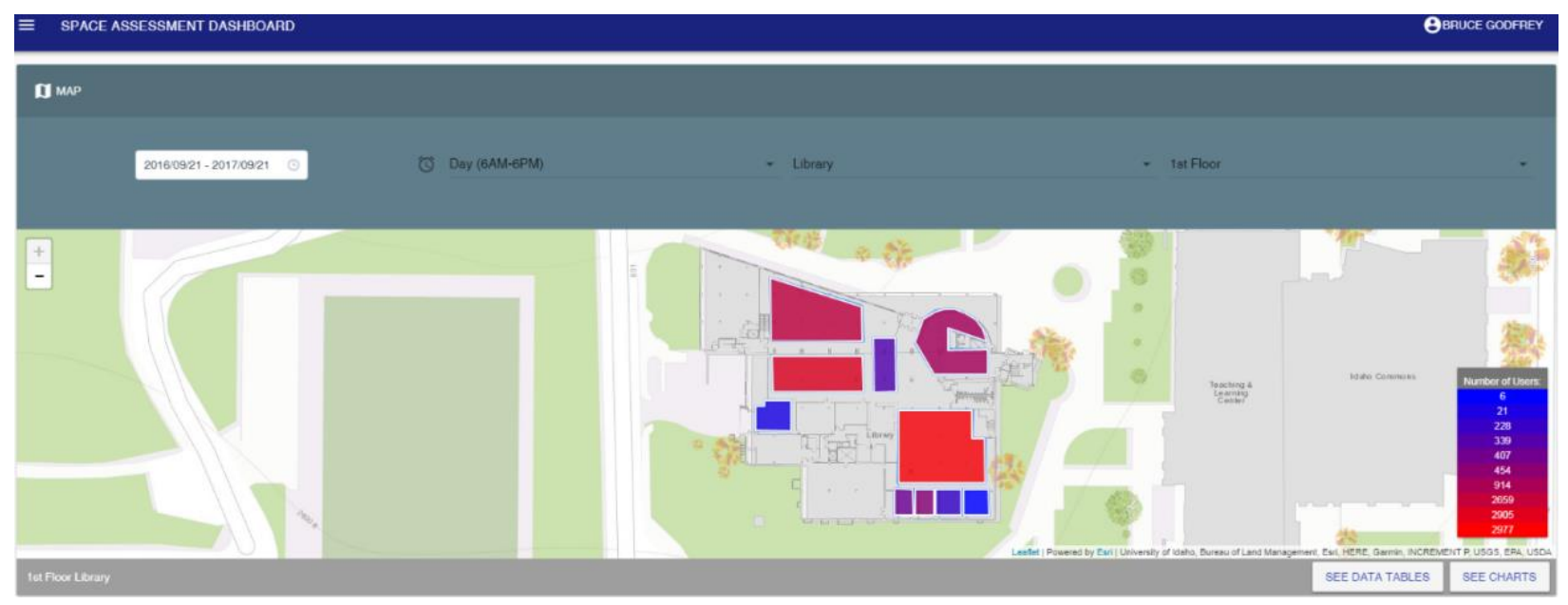

Figure 5. Map view of the space assessment dashboard application. 
For each individual space, a chart and table can be displayed to gain further insight (see figures 5 and 6).

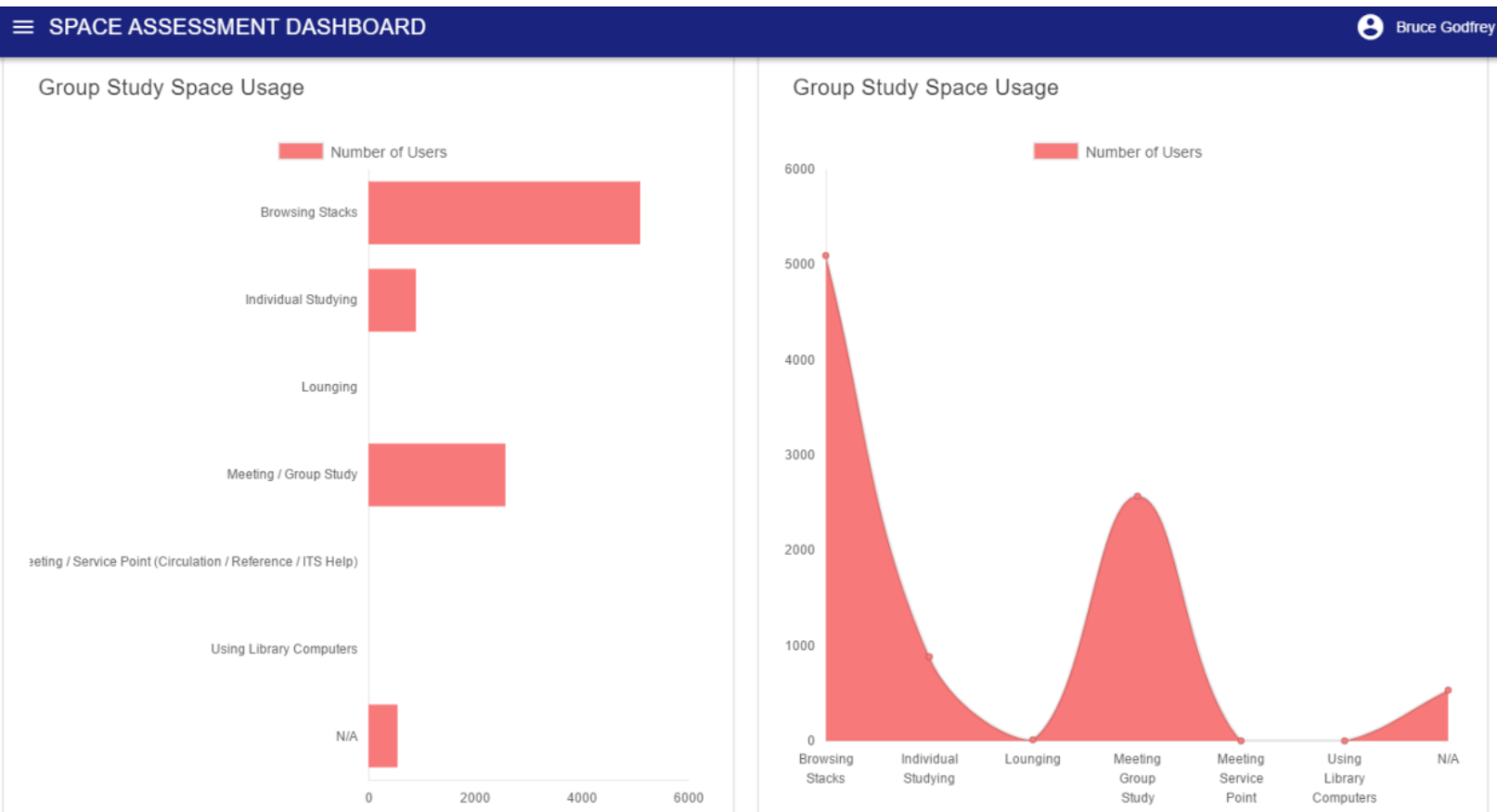

Figure 6. Chart view of the space assessment dashboard application.

\section{SPACE ASSESSMENT DASHBOARD}

Library

Group Study Space Usage

Collection Date $\uparrow$

08/05/2016

0805/2016

08/10/2016

08/10/2016

09/106/2016
(8) Bruce Godtrey

Q

Search

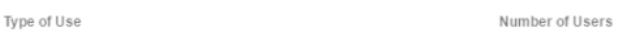

(1)

Browsing Stacks

Meeting / Group Study

Meeting / Group Study

Browsing Stacks

Figure 7. Table view of the space assessment dashboard application.

\section{Limitations: Data-Collection Software Issues}

Using Collector for ArcGIS on devices running Windows 10 proved frustrating because of a documented bug with Collector. A "You are not connected to the internet" error would appear randomly, even when there was a valid internet connection. A workaround was implemented to circumvent the issue, but it was a source of frustration for data-collection staff. Offline data-collection mode was experimented with to see if it was a more favorable option; however, the date and time of the data collection are not captured in offline 
mode, so that potential workflow was abandoned. There were no issues encountered for data collectors who used the Samsung Galaxy (running the Android operating system) or an Apple iPad.

\section{CONCLUSIONS}

Web-based GIS platforms such as ArcGIS Online have evolved to the point where they offer the functionality required for collecting and managing in-library use data. The ArcGIS Online platform performed commendably for this pilot project. While ArcGIS Desktop was used to author the original database schema in this project, it is reasonable to conclude that it is only a matter of time until the functionality required to complete the entire workflow in the web-based platform is available. Using mobile and desktop devices outfitted with the Collector for ArcGIS application proved to be a practical way for collecting real-time in-library use data. Managing project users and the items those users were able to access was straightforward. While the visualization tools for repeated measurements data are currently limited in ArcGIS Online, the data are accessible as a web service, and the sky is the limit on custom webapplication development.

Looking ahead, adjusting schemas to capture height above and below ground level to take advantage of 3D data models and visualization is intriguing. Use of this model may be beneficial for space-assessment projects that seek to gather data more broadly across institutions.

Finally, a noteworthy realization from this research is the potential for inter-institutional and crossinstitution collaboration of library space-assessment projects, or other projects for that matter. Librarians can begin embracing the web GIS movement alongside those in the communities they participate in and serve. Opportunities to create efficiencies are possible through the simple sharing of database schemas. Additionally, the ability for one institution to host a database enabling personnel at multiple institutions, or at multiple libraries at larger institutions, to contribute data is available and ready for further research. 
APPENDIX: SCHEMAS FOR EACH OBJECT IN THE GEODATABASE USED FOR DATA COLLECTION

Building name table and associated domain values

\begin{tabular}{|l|l|}
\hline DomainName & BuildingName \\
\hline Description & Name of the building \\
\hline FieldType & SmallInteger \\
\hline Domain Type & CodedValue \\
\hline & \\
\hline Code & Name \\
\hline 0 & Library \\
\hline 1 & Education \\
\hline
\end{tabular}

Space identifier table and associated domain values

\begin{tabular}{|l|l|}
\hline DomainName & SpaceID \\
\hline Description & Identifier for the area \\
\hline FieldType & String \\
\hline Domain Type & CodedValue \\
\hline & \\
\hline Code & Name \\
\hline $1 \mathrm{~A}$ & Group Study \\
\hline $1 \mathrm{~B}$ & Café \\
\hline $1 \mathrm{C}$ & Landing \\
\hline $1 \mathrm{D}$ & Computer Lab \\
\hline $1 \mathrm{E}$ & Individual/Small Group Study \\
\hline 1F & MILL (134) \\
\hline $1 \mathrm{G}$ & Group Study (133) \\
\hline $1 \mathrm{H}$ & Group Study (132) \\
\hline $1 \mathrm{I}$ & Group Study (131) \\
\hline $1 \mathrm{~J}$ & Classroom (120) \\
\hline
\end{tabular}




\begin{tabular}{|l|l|}
\hline $2 \mathrm{~A}$ & 2nd floor \\
\hline $3 \mathrm{~A}$ & 3rd floor \\
\hline $4 \mathrm{~A}$ & 4 th floor \\
\hline $3 \mathrm{~A} \_1$ & IMTC Area 1 \\
\hline 3B_1 & IMTC Area 2 \\
\hline 3C_1 & IMTC Area 3 \\
\hline 3D_1 & IMTC Area 4 \\
\hline
\end{tabular}

Type of use table and associated domain values

\begin{tabular}{|l|l|}
\hline DomainName & TypeOfUsage \\
\hline Description & Type of usage of the area. \\
\hline FieldType & SmallInteger \\
\hline Domain Type & CodedValue \\
\hline & \\
\hline Code & Name \\
\hline 0 & Browsing Stacks \\
\hline 1 & Individual studying \\
\hline 2 & Lounging \\
\hline 3 & Meeting / Group Study \\
\hline 4 & Service Point (Circulation / Reference / ITS Help) \\
\hline 5 & Using Library Computers \\
\hline
\end{tabular}

Space assessment areas feature class table

\begin{tabular}{|l|l|l|l|}
\hline Field & DataType & Description & Domin \\
\hline GlobalID & GUID & Global Identifier & \\
\hline SpaceID & String & Space Identifier & SpaceID \\
\hline Floor & String & Building Floor & \\
\hline BldgName & SmallInteger & Building Name & BuildingName \\
\hline
\end{tabular}


Space assessment areas observations table

\begin{tabular}{|l|l|l|l|}
\hline Field & DataType & Description & Domin \\
\hline TYPE_OF_USAGE & SmallInteger & Type of Usage & TypeOfUsage \\
\hline NUMBER_OF_USERS & SmallInteger & Number of Users & \\
\hline GlobalID & GUID & Global Identifier & \\
\hline SpaceID & String & Space Identifier & SpaceID \\
\hline COMMENTS & String & General Comments & \\
\hline
\end{tabular}

Space assessment areas feature class to observations relationship class

\begin{tabular}{|c|c|c|}
\hline Cardinality & OneToMany & \\
\hline IsAttributed & FALSE & \\
\hline IsComposite & FALSE & \\
\hline ForwardPathLabel & space_assessment_data & \\
\hline BackwardPathLabel & space_assessment_areas & \\
\hline Description & $\begin{array}{l}\text { Relationship between the space } \\
\text { assessment areas and data } \\
\text { collected }\end{array}$ & \\
\hline Origin Class Name & Origin Primary Key & Origin Foreign Ke \\
\hline space_assessment_areas & SpaceID & SpaceID \\
\hline
\end{tabular}




\section{REFERENCES}

${ }^{1}$ Michael F. Goodchild, "Part 1. Spatial Analysts and GIS Practitioners," Journal of Geographical Systems 2, no. 1 (2000): 5-10, https://doi.org/10.1007/s101090050022.

${ }^{2}$ Pinde Fu and Jiulin Sun, Web GIS: Principles and Applications (Redlands, CA: Esri, 2011), 7.

3 Suzana Dragićević, “The Potential of Web-based GIS," Journal of Geographical Systems 6, no. 2 (2004): 7981, https://doi.org/10.1007/s10109-004-0133-4.

${ }^{4} \mathrm{Fu}$ and Sun, Web GIS, 9.

5 “Who We Are," Esri, accessed October 17, 2017, http://www.esri.com/about-esri\#who-we-are.

${ }^{6}$ Ningning Kong, Michael Fosmire, and Benjamin Dewayne Branch, "Developing Library GIS Services for Humanities and Social Science: An Action Research Approach," College \& Research Libraries 78, no. 4 (2017): 413-27, https://doi.org/10.5860/crl.78.4.413.

${ }^{7}$ Bradley Wade Bishop and Lauren H. Mandel, "Utilizing Geographic Information Systems (GIS) in Library Research," Library Hi Tech 28, no. 4 (2010): 543, https://doi.org/10.1108/07378831011096213.

${ }^{8}$ Jingfeng Xia, “Library Space Management: A GIS Proposal,” Library Hi Tech 22, no. 4 (2004): 375, https://doi.org/10.1108/07378830410570476.

9 Jingfeng Xia. “GIS in the Management of Library Pick-up Books," Library Hi Tech 22, no. 2 (2004): 209-16, https://doi.org/10.1108/07378830410543520.

${ }^{10}$ Jingfeng Xia, “Visualizing Occupancy of Library Study Space with GIS Maps,” New Library World 106, no. 5/6 (2005): 219-33, https://doi.org/10.1108/03074800510595832.

11 Jingfeng Xia, "Locating Library Items by GIS Technology," Collection Management 30, no. 1 (2005): 63-72, https://doi.org/10.1300/J105v30n01_07.

12 Lauren H. Mandel, “Geographic Information Systems: Tools for Displaying In-Library Use Data,” Information Technology \& Libraries 29, no. 1 (2010): 47-52, https://doi.org/10.6017/ital.v29i1.3158.

${ }^{13}$ Andrew Coyle, “Interior Library GIS," Library Hi Tech 29, no. 3 (2011): 529-49, https://doi.org/10.1108/07378831111174468.

${ }^{14}$ Lisa M. Given and Heather Archibald, "Visual Traffic Sweeps (VTS): A Research Method for Mapping User Activities in the Library Space," Library \& Information Science Research 37, no. 2 (2015): 100-108, https://doi.org/10.1016/j.lisr.2015.02.005.

15 “Suma," North Carolina State University Libraries, accessed October 17, 2017, https://www.lib.ncsu.edu/projects/suma.

16 "What Is a Geodatabase?," Esri, accessed October 17, 2017, http://desktop.arcgis.com/en/arcmap/10.4/manage-data/geodatabases/what-is-a-geodatabase.htm. 
17 “Geodatabase Design Steps,” Esri, accessed October 17, 2017, http://desktop.arcgis.com/en/arcmap/10.4/manage-data/geodatabases/geodatabase-designsteps.htm.

18 "Hosted Layers," Esri, accessed October 17, 2017, http://doc.arcgis.com/en/arcgis-online/sharemaps/hosted-web-layers.htm. 